\title{
Abstracting Grammar From Social-Cognitive Foundations: A Developmental Sketch of Learning
}

\author{
Paul Ibbotson \\ University of Manchester
}

\begin{abstract}
Although the understanding of the development of infants' social cognition and cooperative reasoning has progressed significantly, to date, it has yet to be worked through in any detail how this knowledge interacts with and constrains emerging syntactic representations. This review is a step in that direction, aiming to offer a more integrated account of the learning mechanisms that support linguistic generalizations. First, I review the developmental literature that suggests social-cognitive foundations get linguistic constructions "off the ground." Second, I focus on building layers of abstractions on top of this foundation and the kind of cognitive processes that are involved. Crucially important in this explanation will be the fact that humans possess a unique set of social-cognitive and social motivational-skills that allows language to happen. Furthermore, early linguistic categories are formed around the underlying functional core of concepts and on the basis of their communicative discourse function. This, combined with powerful pattern-detection skills, enables distributional regularities in the input to be paired with what the speakers intend to communicate.
\end{abstract}

Keywords: language acquisition, grammar, social-cognition, pattern-finding

Putting together novel expressions is something that speakers do, not grammars. It is a problem-solving activity that demands a constructive effort and occurs when linguistic convention is put to use in specific circumstances. (Langacker, 1987, p. 65)

The starting point for this review is a current weakness of usage-based theories of language acquisition; the need to specify in greater detail the learning mechanisms that underpin generalizations. Although the understanding of the development of infants' social cognition and cooperative reasoning has progressed significantly in recent years, to date, it has yet to be worked through in any detail how this knowledge interacts with and constrains emerging syntactic representations. This paper is a modest step in that direction, aiming to offer a more integrated account of the learning mechanisms that support linguistic generalizations.

As the most historically controversial issue is whether infants can ever get to an adult grammar inductively, each shift on the continuum from input to abstraction needs to be carefully justified with respect to the social-cognitive abilities of the infant and the properties of the input at that phase when the shift happens. As a test case, I use the example of the caused-motion construction, the meaning of which can be paraphrased as " $\mathrm{X}$ causes $\mathrm{Y}$ to move to Z," for example "he's pushing the ball to Mary" or "Frank sneezed the tissue off the table" (Goldberg, 1995).

It needs to be stated from the outset that, crucially, where human communication differs from other domains of pattern finding, is

I thank Anna Theakston, Elena Lieven, Adele Goldberg, Claire Noble and an anonymous reviewer who provided insightful comments on earlier drafts of this paper.

Correspondence concerning this article should be addressed to Paul Ibbotson, Max Planck Child Study Centre, Coupland 1 Building, Coupland Street, Oxford Road, Manchester M13 9Pl England. E-mail: paul.ibbotson@manchester.ac.uk that generalizations take place within the bounds of cooperative reasoning and communicative norms, established between a communicator and recipient. Other authors have pointed out that possessing a powerful set of social-cognitive and social-motivational tools is logically prior-both in the development of the species and the development of the individual — to recipients treating utterances as language and not just a string of sounds (e.g., Tomasello, 2008). This characterization of the "top-down" psychology is crucial if there is going to be a convincing account of how grammar is constructed "bottom-up" from usage events.

This view of cognitive organization has important implications for language learning in general and learning abstract grammatical patterns in particular. For a start, the default psychological status is that a communicator's utterances will have referential intention; a communicator wants the recipient to attend to something: an action, an object, some aspect of the scene, the speaker's attitude toward a scene, or a proposition. Second, the communicator also is likely to have a social motive for doing so: I want you to do something, to feel something, to know something, or to share something that I think you will find useful or interesting, and this assumption of helpfulness guides your search for communicative relevance (Sperber \& Wilson, 1986, 1995; Tomasello, 2008). Finally, in ongoing discourse these communicative acts are modified by what the speaker-recipient know together, the common ground and joint attention that they have established over the course of their communicative history.

To have this in mind when looking at the schematization of grammatical categories is important as many of the claims about the processes involved here-distributional analysis, categorization, analogy - are likely to be true of other species (and computers). However once our view of language, and more generally of communication, is one of a social act, it is possible to say why domain-general cognitive processes and even species-general processes might be necessary but not sufficient for language acquisition. The social-pragmatic underpinnings of language acquisition 
have been emphasized before (e.g., Bruner, 1983; Nelson, 1985; Tomasello, 1992) but in this paper I try to go further, suggesting that linguistic categories are artifacts that emerge in development from a handful of cognitive skills (e.g., perception, attention, pattern-finding, memory) interacting in complex ways with a species-specific set of social skills (e.g., shared intentionality, cooperative reasoning, cultural intelligence).

\section{Bootstrapping Meaning From Usage Events}

Above all, language acquisition involves learning a skill. Part of this skill involves solving an abstract problem. To understand the communicative content of an utterance, the infant has to work out which chunks of sound do what. All theories agree the learning mechanisms underpinning this process must be powerful enough for children to learn the particular form-meaning relationships of any one of 6,000 plus languages they are born into. Where theories have traditionally tended to differ, is whether the language provides the raw materials from which children build their linguistic inventories or whether it provides the trigger for preexisting linguistic representations.

Generative linguists following Chomsky (e.g., Chomsky, 1975; 1980 ; 1995) considered language to have certain structural properties that are so abstract, so complex, and the principles that govern them so subtle and highly specific to their purpose, that in principle they could not possibly be learned-this is the argument from the "poverty of the stimulus." This is true in some sense if one has a narrow definition of what "the stimulus" is. If, however, one considers language as a set of resources available to share and direct attention-part of a broader adaptation for collaborative activity and cultural life in general-then there is a wider range of cues available to the learner. The central idea here is that language is a code that rests on a deeper code about how people work. We understand the mundane utterance "can you pass the salt?" as a transparent request rather than, say, as an enquiry about condiment passing abilities because we can work out what is relevant from the communicator's perspective. One way to work out what's relevant is to have a model in the recipient's head of the communicator's intentions, goals, beliefs, desires, and attitudes. This overall view of development predicts there should be a close correspondence between language emergence and social-cognitive abilities and indeed research shows children's emerging linguistic skills are predicated on their ability to engage in nonlinguistically mediated joint attentional activities (e.g., Bakeman \& Adamson, 1984; Bruner, 1983; Carpenter, Nagell, \& Tomasello, 1998; Smith, Adamson, \& Bakeman, 1988; Tomasello, Mannle, \& Kruger, 1986; Tomasello \& Todd, 1983; Trevarthen \& Hubley, 1978).

Figure 1 introduces the grounded usage event (a referential context-form-function assembly) that I use to show how a causedmotion construction could reach abstraction. With many everyday concepts and events being indicated by linguistic conventionsincluding argument-structure constructions - the nature of this perceptually grounded usage event becomes crucial. At the bottom of the Figure 1 there are simplified caused-motion scenes. At the risk of taking the construction metaphor too far, the events that take place in a communicative context are the "ground floor" of the symbolic assembly and are especially important in learning early on in development. The events in question all share something in common, shown in the diagram as a dashed line; the actors behave

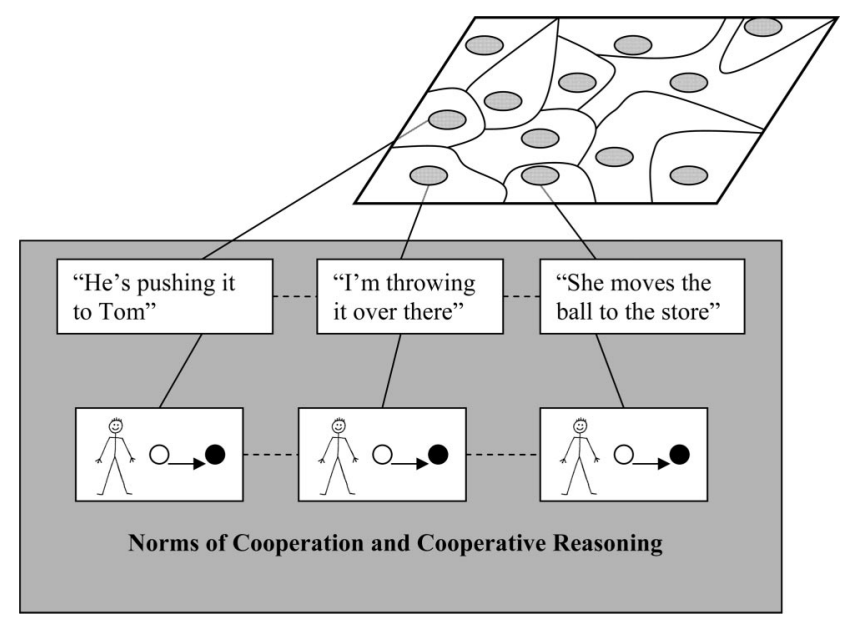

Figure 1. Events associated with utterances, mapped onto a plane of usage events.

in a similar way and their actions are intended to accomplish something similar. Buresh and Woodward (2007) provided evidence that language has an important role in generalizing actions across multiple actors. Using a visual habituation paradigm to assess infants' tracking of goals, they tested whether infants represented goals as specific to particular agents. Thirteen-month-old infants restricted reaching goals to particular agents, but generalized a conventional linguistic action, labeling, across agents. A 9-month-old showed the former pattern but not the latter. This shows infants had begun to delimit the person-general and personspecific components of goal-directed action by the end of the first year of life. They argued this ability provides a foundation for social reasoning by enabling infants to predict and interpret actions online by relating a person's prior and current behaviors, and distinguishing those behaviors from those of other persons. Thus, early on intention-reading skills provide important cognitive foundations on which later abstractions are formed, including those that will go on to become grammatical schemas.

\section{Cognitive Skills: Analogy, Categorization, and Schematization as Pattern Finding}

Humans are prodigious pattern finders. We are constantly organizing experience into clusters of things that look the same or do the same thing, from the relatively abstract generalizations of grammar to the more prosaic; for example, when a 6-year-old realizes that tulips must need water because people do ${ }^{1}$ (Inagaki \& Hatano, 1987). In this example, the two things being compared or "analogized" fall under a category of things that share a property (needing water). It suggests we might want to draw a distinction between processes of analogy, categorization, and schematization, and indeed they are often talked about in different terms in the cognitive literature. For example, there seems to be a difference between categorization - typically thought of as "vertical" rela-

\footnotetext{
${ }^{1}$ Inagaki and Hatano (1987) also reported that $40 \%$ of kindergarteners believe that a tulip can "feel happy" and $72 \%$ believe that a tulip can "feel pretty."
} 
tionships in a taxonomic hierarchy in which $\mathrm{X}$ and $\mathrm{Y}$ are instances of $\mathrm{Z}$, and $\mathrm{Z}$ is schematic of $\mathrm{X}$ and $\mathrm{Y}$; and analogy-typically "horizontal" relationships that do not involve a literal relabeling of what $\mathrm{X}$ is an instance of, rather, the operation is more like $\mathrm{X}$ is like $\mathrm{Y}$ in way $\mathrm{Z}$. However, the suggestion here is that there is no distinction between these processes assuming that (linguistic) knowledge is organized in something as a hierarchy of schemainstance relationships.

In the above example, the schematic structure one is talking about in both cases is the same. In analogy, if $\mathrm{X}$ is like $\mathrm{Y}$ in a way $\mathrm{Z}$, then $\mathrm{Z}$ can be considered schematic of $\mathrm{X}$ and $\mathrm{Y}$ and if $\mathrm{Z}$ is schematic of $X$ and $Y$ then these have been treated as instances of the category Z. For example, one can make the analogy that the planets orbit the solar system like electrons orbit a nucleus. It seems like a clear case of analogy, but if in the mind of a speaker there was a word for the concept of things behaving in this way, then it looks more like a categorization. One could say an analogy is a category you do not have a name for (yet). Either way, it seems "pattern finding" captures the essence of categorization, schematization, and analogy, and in terms of the output of the cognitive operations ( $\mathrm{X}$ is like $\mathrm{Y}$ in way $\mathrm{Z}$ ) they can be treated as equivalent.

\section{Finding Patterns in Events}

Mandler $(1992,2004)$ suggested that prior to language, infants construct image schemas that store fundamental components of an event. These image schemas are a kind of perceptual redescription of an event that is analyzed within the infant's attention. Some of the most common image schemas are constructed around relational components of dynamic events that are codified across languages, including: containment support (putting things in a container vs. putting things on a surface), path manner (the trajectory of the action with respect to the ground vs. how the action is performed), source goal (beginning point of an event vs. its ending point), and figure ground (the moving or conceptually movable point vs. the reference entity or stationary setting; Choi \& Bowerman, 1991; Jackendoff, 1983; Lakoff, 1987; Langacker, 1987; Talmy, 1985, 2000). According to Mandler these common image schemas were later combined to derive basic conceptual categories such as animacy, causality, and agency.

Although these concepts are universally expressed, different languages encode them in different ways. The infant's job is to work out how their language - typically with verbs and prepositions-packages these concepts (Gentner, 1982; Gentner \& Bowerman, 2009). Goksön, Hirsh-Pasek, and Golinkoff (2010) showed that for some basic image schemas, infants start with languagegeneral concepts that are gradually construed in language specific ways. Infants parse events and generalize components of these events in ways that lay the groundwork for the learning of relational terms such as verbs and prepositions (Lakusta, Wagner, O'Hearn, \& Landau, 2007; McDonough, Choi, \& Mandler, 2003; Pulverman, Golinkoff, Hirsh-Pasek, \& Sootsman-Buresh, 2008). Goksön et al. (2010) argued that sensitivity to these basic constructs (such as figure vs. ground, source vs. goal), is universal in two senses: (a) irrespective of the language environment in which infants are raised, they detect nonlinguistic components of events, and (b) infants attend to fine-grained distinctions in events even when these are not codified in their native language (Goksun, Hirsh-Pasek, \& Golinkoff, 2008; Hespos \& Spelke, 2004). This is in the spirit of Kemmer's (2003) cognitive typology approach where the basic idea is that recurrent typological patterns reveal the distinctness of a number of basic contrasting types of event to which human beings are sensitive. These conceptual categories are used in the chunking and organization of conceptual information for the purposes of formulating, manipulating, and communicating thought (Kemmer, 2003).

So, early on in development how events are construed in mental space (the conceptualization, Figure 2) bears some relation to how they are construed in perceptual space (the simplified scenes at the bottom of Figure 1). Figure 2 shows the embodied form of the event representation or construal as a redescribed form of the perceptual scenes (the starting point for utterance-event associations) tagged with the psychological characteristics of the actors involved. In terms of the caused-motion construction, there is evidence that people represent causation as patterns of force paying particular attention to the dynamics of the event (Talmy, 1985, 1988). Because dynamic properties can be sensed, a physicalist approach to causation not only grounds causation in the world (the simplified scenes at the bottom of Figure 1), it also explains how causation might be experienced in our own bodies, and why such

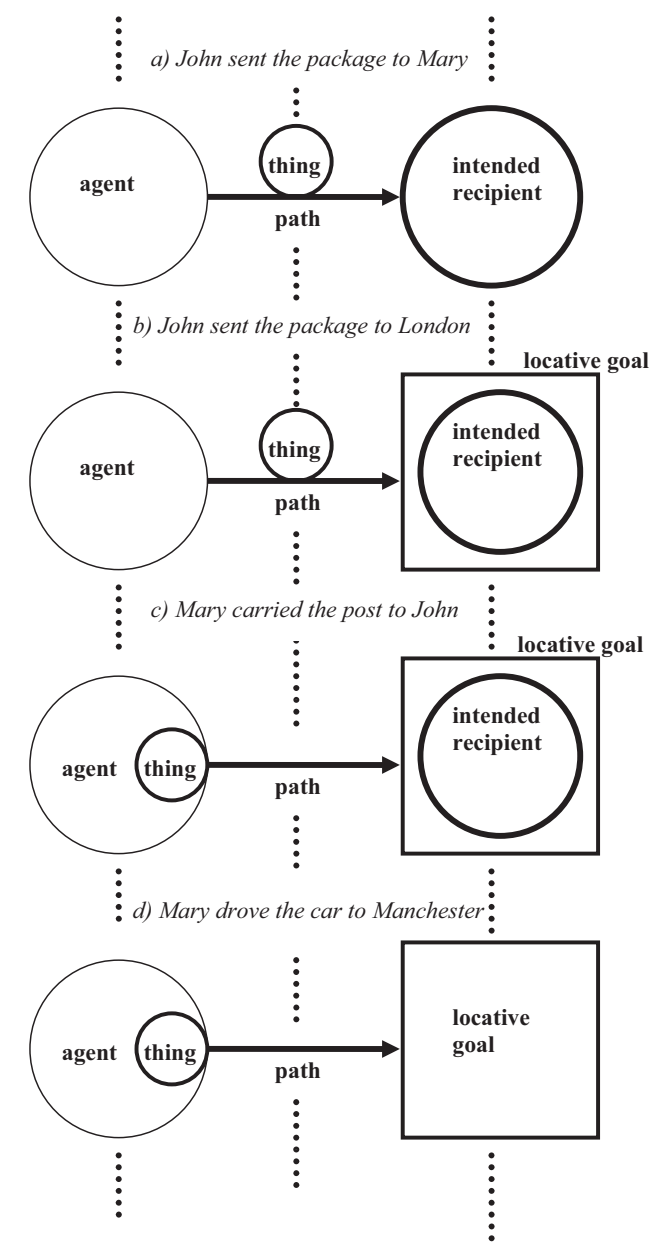

Figure 2. The functional alignment of constructions based on their event construal; the relevant domain of analogy for argument-structure constructions. 
notions of causal power, energy, and force are not just side effects of statistical dependencies (Wolff, 2007). Argument structures are differentiated into different families of use on the basis of these properties, such as "X cause Y to move to Z." At no point along the continuum of descriptions and redescriptions are there the meaningless rules posited by more formal accounts interacting with meaningful words, rather, at some point children begin to make categorization decisions based on the relationship between participants in an event-for the caused-motion construction this means they realize this particular type of utterance is an example of a convention that is put to use where the intention is to communicate " $\mathrm{X}$ causes $\mathrm{Y}$ to move to $\mathrm{Z}$," this is pattern finding based on "things are what they do" (Nelson, 1983, 1996).

Figure 2 shows how the functional alignment of arguments could work for some utterances that fall under a general causedmotion schema, elaborated from Lakoff and Johnson's (1999, p. 32) source-path-goal schema (see also Kodama, 2004). There is good evidence that the alignment of relational structure and mapping between representations is a fundamental psychological process underlying analogy and similarity (Gentner \& Markman, 1993, 1994, 1995; Goldstone, 1994; Goldstone \& Medin, 1994; Goldstone, Medin, \& Gentner, 1991). For example, when the learner is trying to comprehend the two transitive sentences the "the goat ate the woman" and "a woman tickled a goat," they do not begin by aligning elements on the basis of the literal similarity between the two goats, but match the goat and the woman because they are both construed as playing similar roles (including psychological roles) in the event, such as actor or undergoer. There is quite a lot of evidence that people, including young children, focus on these kinds of relations in making analogies across linguistic constructions, with some of the most important being the meaning of the words involved, especially the verbs, and the spatial, temporal, and causal relations they encode ${ }^{2}$ (e.g., Gentner \& Markman, 1997; Gentner \& Medina, 1998; Tomasello, 2003).

In the usage-based view of language acquisition, children first acquire a number of low-scope verb schemas (e.g., X hits Y, X kisses $\mathrm{Y}, \mathrm{X}$ pushes $\mathrm{Y}, \mathrm{X}$ pulls $\mathrm{Y}$, etc.), then by forming analogies between the roles that participants are playing in these events, these item-specific constructions eventually coalesce into a verbgeneral abstract construction (Tomasello, 1992, 2003). Thus the process of verb-specific, "local" knowledge being redescribed and recategorized at a later stage by more abstract "global" schemas is equivalent-in representational redescription terms (KarmiloffSmith, 1979, 1992)—to knowledge being initially in the system, but not yet available to the system.

One manifestation of this domain-general process allows interconstruction mappings and is shown by the vertical dotted lines shown in Figure 2. They are analogies/categorizations in the sense that $\mathrm{X}$ is like $\mathrm{Y}$ in way $\mathrm{Z}$ : Utterance a) is like utterance $\mathrm{b}$ ) in that they construe the agent, thing, and path in similar ways; utterance b) is like c) in that they construe path and goal in a similar way; and utterance c) is like d) in that they construe agent, thing, and path in a similar way. They are placed in this order as a) is more like b) than it is like c) or d) with respect to the relationship between participants; b) is more like c) than it is like d) and so on.

This is where social cognition interacts in complex ways with developing syntactic representations. Every theory of language acquisition needs a way of constraining generalizations because in theory there are an infinite number of grammars compatible with a set of sentences. The dotted lines (see Figure 2) above represent the social-cognitive framework over which generalizations take place in this approach. The vectors of generalizations and the dimensions in which analogies extend are constrained by the psychological tagging on this framework and the embodiment of the event "X causes $\mathrm{Y}$ to move to Z" as patterns of force, paths, and objects.

More important, the model framework is also tagged with psychological descriptions such as agent, goal, and intention. The goals and intentions of people do not present an infinite range of equally relevant generalizations with respect to the common (communicative) ground established between communicator and recipient. The ability to represent such psychological states is predicated by a fundamental social ability of shared intentionality and intersubjectivity (Tomasello, 2003). In Figure 2, the socialcognitive framework is also populated with a basic conceptual repertoire that is able to represent such things as objects, forces, goals, causes, paths, substances, space, and time-the types of things that language after language encodes ${ }^{3}$ (Allan, 1977; Bybee, 1985; Denny, 1976; Pinker, 1989; Talmy, 1985).

Therefore, learning grammar is thought of here as pattern finding over these types of concepts and image schemas, but it is also more than that. Because psychological states are also tagged onto this framework it is pattern finding through a unique socialcognitive lens, allowing us to see patterns that no other species can while making other possible patterns deeply unintuitive or not entertained at all. Abstract grammatical patterns are conventionalized patterns of shared experience; patterns of experiences that can be organized on the basis of behavior, for example whether their actions are intended to accomplish something similar. Thus right from the start, wider knowledge of how people work is brought to bear on finding patterns in grammar.

As stated, the aim of this paper is to begin to see how integrating social and grammatical representations can advance usage-based theory. This approach is in contrast to previous attempts to explain generalizations and constraints in language acquisition by appealing to the general learning processes involved, for example, subset principle (Berwick, 1985), preemption (Braine, 1971), entrenchment (Braine \& Brooks, 1995), hierarchical Bayesian modeling (Perfors, Tenenbaum, \& Wonnacott, 2010). None of these approaches integrate a unique social-cognitive aspect into their model and, to be clear, what is being proposed here is not incompatible with these approaches-they may be necessary but not sufficient. This is because, as far as we know, human language occupies a unique social-cognitive niche, the suggestion is that the

\footnotetext{
${ }^{2}$ Analogy also operates in a more abstract sense, by extending the prototypical meaning of constructions. For example, the meaning of the ditransitive construction is closely associated with "transfer of possession" as in "John gave Mary a goat." Metaphorical extensions of this pattern, such as "John gave the goat a kiss" or even "Cry me a river" are understood by analogy to the core meaning of the construction from which they were extended, which in the case of the ditransitive is something like " $\mathrm{X}$ causes Y to receive Z"' (Goldberg, 2006).

${ }^{3}$ Under this account typological similarities emerge as the result of a type of convergent cultural evolution, in which different language communities have arrived at similar communicative solutions-for example, pronouns, word order, morphology, anaphora-to similar communicative problems-for example, sharing, informing, and requesting.
} 
answer to constraining generalizations also needs to be as species specific (but one that doesn't need universal grammar either).

Integrating the social and the syntactic has started to take place in a limited way in the developmental literature. For example, the reading of intentions has been shown to narrow the scope of possible candidate concepts for verb learning (e.g., Papafragou, Cassidy, \& Gleitman, 2007; Poulin-Dubois \& Forbed, 2002; Tomasello \& Barton, 1994). In noun learning, children can use eye-gaze, head posture, and gesture to infer speakers referential intention (e.g., Baldwin, 1991) and more generally can interpret actors' intentions about actions (e.g., Carpenter, Akhtar \& Tomasello, 1998; Gergely, Bekkering \& Király, 2002; Woodward \& Sommerville, 2000). Moreover, just prior to speaking, adults are more likely to look at the subject of their sentence than any other character (Gleitman, January, Nappa \& Trueswell, 2007; Griffin \& Bock, 2000). This raises the possibility that children could use this cue in the input, probabilistically at least, to build a correspondence between the perspective of an event and how that perspective is expressed in their language.

Nappa, Wessel, McEldoon, Gleitman and Trueswell (2009) showed that 3-, 4- and 5-year-olds used the eye-gaze of the speaker to infer the meaning of novel relational verbs (of the type chase vs. flee) in linguistically uninformative contexts (e.g., He's mooping him). Thus a speaker who looked at the chaser increased the children's "chase" responses and decreased "flee" responses and the opposite effect was found when a speaker looked at the flee-er. When the speaker was linguistically informative (the rabbit's mooping the elephant/the elephant's mooping the rabbit) the effect of speaker's gaze on meaning was negated for the older groups and minimal for the youngest, even though all ages continued to track the gaze of the speaker (as measured by eye-tracking). When the linguistic and social cues conflicted even the youngest children (3 years) went with the linguistic cue to interpretation. I find it interesting that Nappa et al. also observed a nonsignificant developmental trend in the cue conflict condition such that older children were more likely than younger children to use syntactic evidence to guide verb decisions. In summary, a range of experiments demonstrate that the manipulation of attention to the referents in an event influences structural choices during sentence production.

It is noticeable that the sequential (horizontal) aspects of event representation on the social-cognitive framework (see Figure 2) are analogous to the syntagmatic dimensions of Saussure (1916) the way participants in an event relate to one another spatially, temporally, and causally. The paradigmatic dimension is analogous to the space in which concepts are formed on the basis of substitutability in events (the vertical aspects in Figure 2). These have been called slot-filler categories and emerge in development when infants learn about what types of things can participate in the roles in such events (see Nelson, 1996, for a review). Thus the formation of linguistic categories-both syntagmatic categories such as agent and patient and paradigmatic categories such as noun and verb - can be seen in the same basic terms as the formation of nonlinguistic (or semantic) categories. When a number of exemplars show systematic variation they can be analogized as instances of a more general pattern where the linguistic items play similar communicative roles, in what Tomasello (2003) called functionally based distributional analysis. This account is especially attractive in explaining how young children form superor- dinate categories, such as food and furniture whose members share little in common perceptually. Food consists simply of those items that play a certain role in children's breakfast, lunch, and dinner scripts. Therefore, schematization of argument-structure constructions is driven at the conceptual level by shared elements of the event representation, for example, the manner and path of objects, the distinguishability and number of the participants, and somewhat more abstract relationships such as the attitudes of participants to what is being communicated (e.g., I think X, I know X).

Linguistic categories such as noun-hood, verb-hood, and complement-hood emerge from the embodied event representations (conceptualizations). Embodied in this context simply emphasizes that cognition is a situated activity: Abstract symbols acquire real-world meaning by ultimately being grounded in terms of the agent's experience and physical characteristics. Developmental psychologists and linguistics have asked "given an infinite number of generalizations a child could make, why do they make the ones they do?" The embodied view of cognition combined with the social-cooperative model of communication shows why an infinite number of generalizations are not available to the learner to begin with.

To return to the specific example of the caused-motion construction, the idea that argument-structure analogy needs to take place at this level of abstraction does not deny that infants are also developing rich lexical representations; clearly, one utterance is potentially analogous to other utterances across multiple domains (see Figure 3). The main point here is that when it comes to schematizing the relationships between participants, the functional alignment based on participant roles is the only domain of analogy that leads to argument-structure grammaticalization.

Figure 3 shows that for one utterance, "the man sneezed the foam off the latte," there are formal-surface analogies to the lexical representations of sneezing and functional analogies that operate on the alignment of event-roles-key to the schematization of argument-structure construction. When the participants are identified and aligned with previous utterances (cf. Figure 2), "she pushed the glass into the sink" out-competes "she sneezed" when the goal of the system is to find an analogous functional template (cf. relational mapping, e.g., Gentner \& Markman, 1993, 1994, 1995).

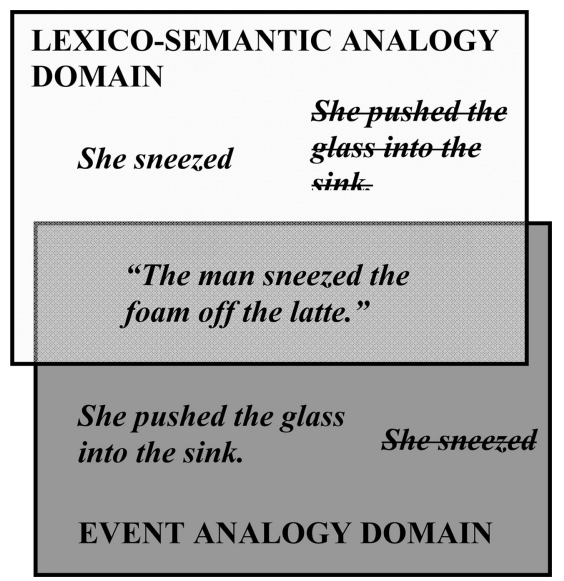

Figure 3. Multiple domains of competing analogies. 


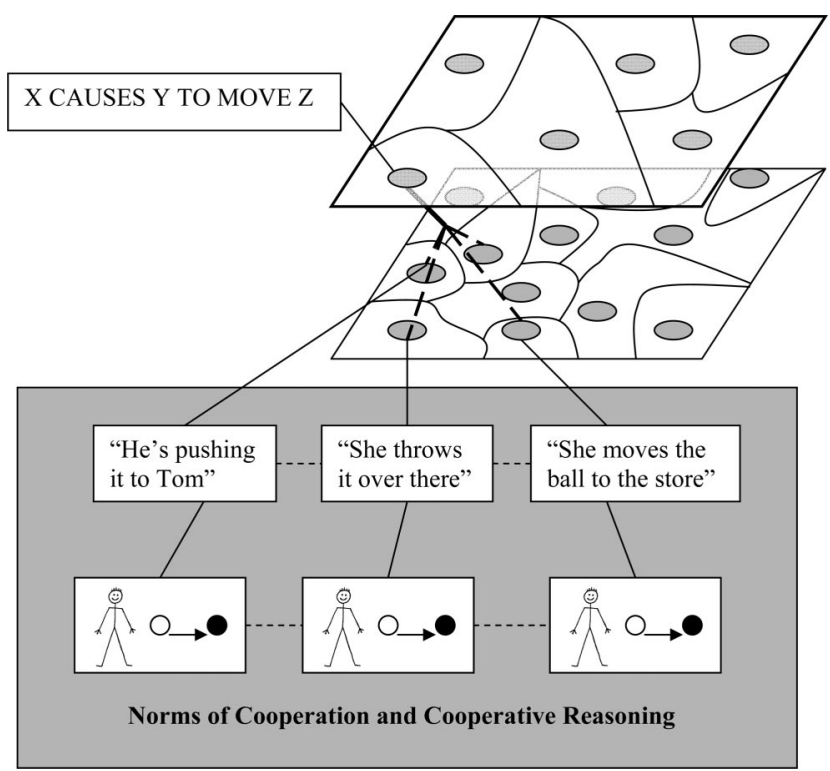

Figure 4. The second tier of abstraction generalizes over caused-motion event-utterance co-occurrences.

In the beginning, the infant's attention is directed by a number of processes to the role that participants are playing in an event. By accumulating a history of these usage events the infant has begun to learn the particular functional distributions of utterance-event co-occurrences in her language.

\section{Distributions}

This review has spent a disproportionate amount of time on the first level of abstraction, getting constructions off the ground as it were because the social-cognitive foundations on which later grammatical abstractions are built are so important. What these generalizations look like in development will be heavily influenced by the characteristics of the input (e.g., token frequency, type frequency, type/token ratio, reliability, schema complexity). In other words, if this type of social-cognitive pattern detection is driving generalizations, properties of the input determine how difficult that pattern is to detect.

By adding an extra plane of abstraction I am saying that a number of usage-events have been identified as having properties in common that are in some way predictive of how they behave-it is worth abstracting over them (in the figures $1,4,5, \& 6$, the lines connecting one plane of abstraction to another). For a causedmotion construction, a reasonable inductive generalization that follows from "X cause $\mathrm{Y}$ to move Z" might involve animacy (see Figure 4). It is a generalization in the sense that the category of animate things affecting inanimate things is greater than the class of caused-motion events. There is no one-to-one relationship here, not all caused-motion expressions are going to have animate subjects lexically realized (e.g., the ball hit the cup off the table) and clearly not all animate subjects are involved in a caused motion event, however, as actions are prototypically interpreted as an attempt to accomplish a goal, and goals are correlated with animate things, it seems an animacy association that would have some abstraction value. Moreover, infants' knowledge of animacy could in theory constrain assignment of semantic object roles in the caused-motion construction to plausible candidates. This is a probabilistic nondeterministic influence on role assignment; compare "John throws the ball to Mary" versus "Mary throws John to the ball." What is meant by "some abstraction value"?

First, it is resource efficient to incorporate a potentially infinite number of individuals into a smaller number of classes: This is something that is presumably important to a mind/brain with a finite amount of energy at its disposal and a finite amount of time, for practical communicative reasons, in which to comprehend and produce an utterance in the discourse. Second, this ability supports an organized schema-instance taxonomy and by knowing some properties you can infer some other properties freely because members of the same class are assumed to share some unobserved properties.

Is this abstraction a reasonable assumption given what is known about the cognitive capacities of young infants? Children have strong expectations about the capacities of animate and inanimate entities from an early age, for example, toddlers know that animate entities can move on their own while inanimate things cannot (Golinkoff, 1975; Massey \& Gelman, 1988). Moreover, they can also recruit this information for the purpose of role assignment in argument-structure constructions (Becker, 2007; Gelman \& Koenig, 2001). It is not surprising then that a number of theorists have proposed that the linguistic system has a tendency to align particular semantic roles with different levels of animacy (e.g., animate $\rightarrow$ agent, inanimate $\rightarrow$ patient; Aissen, 1999; Dowty, 1991) Presumably, the fact that languages with such different lineages as Hindi, Finnish, Russian, Samoan, Dyirbal, Apachean, and Papuan

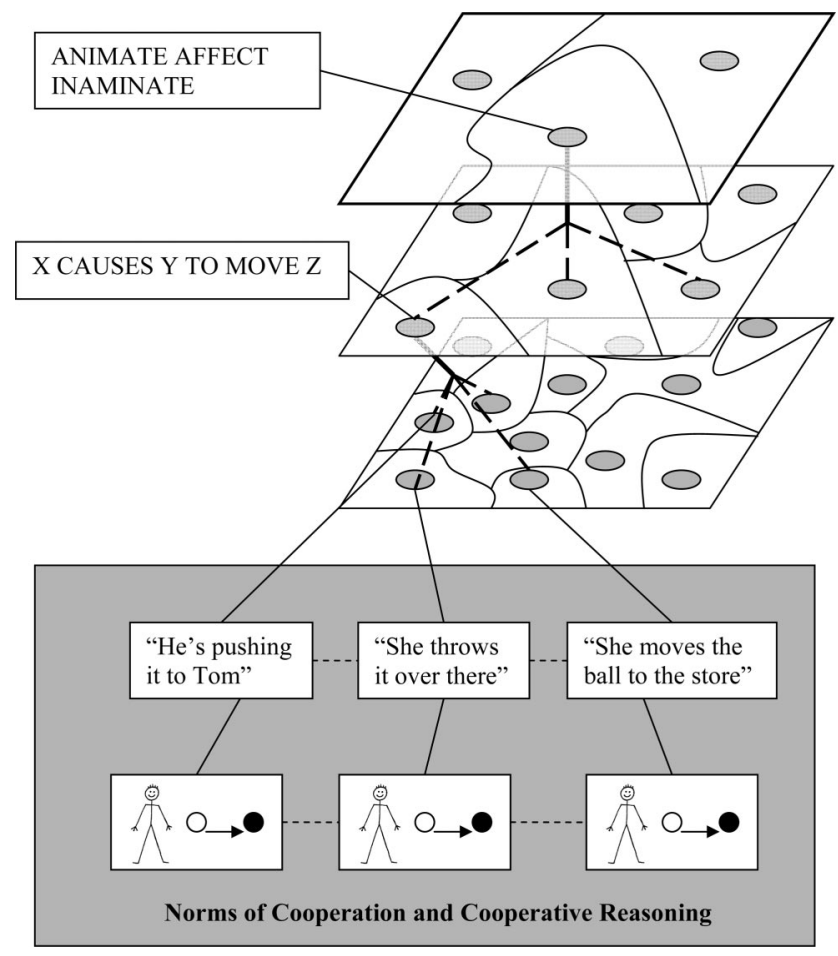

Figure 5. The generalization of animacy over caused-motion schema. 
have evolved to grammaticalize this feature, reflects the fact that carving the world into animate and inanimate categories is powerfully predictive of how things behave and thus buys some information free (see Comrie, 1981; Kibrik, 1985; Mallinson \& Blake, 1981; Song, 2001, for various discussions on the communicative function of animacy). This is particularly so in the realm being discussed here of the caused-motion event in which acting and being acted on are salient features of the scene.

The most abstract superschema " $\mathrm{X}$ cause $\mathrm{Y}$ " considered here (see Figure 6) will of course be schematic of many other constructions in this network such as the ditransitive ( $\mathrm{X}$ cause $\mathrm{Y}$ to receive $\mathrm{Z}$-John emailed Susan the attachment) and the resultative (X causes $\mathrm{Y}$ to become $\mathrm{Z}$ - she drank herself to death). Using these abstraction planes makes it clearer to see how families of constructions or patterns of use are related by the overlap of connections in the network, for example, ditransitives, resulatives, and caused motions are all "dominated" by "X cause Y." One of the advantages of construction grammar is that it recognizes languages use grammaticalized prefabricated packages as time-saving devices that structure the contents of what is communicated in a schematized form. This insight - that constructions themselves carry meaning - can neatly explain why some utterances have the meaning they do. For example, the verbs in "Sam helped him into the car," "She let the water out of the bathtub," and "Frank sneezed the tissue off the table" cannot be said to mean "X cause $\mathrm{Y}$ to move Z"- they are not causative independent of the construction. The

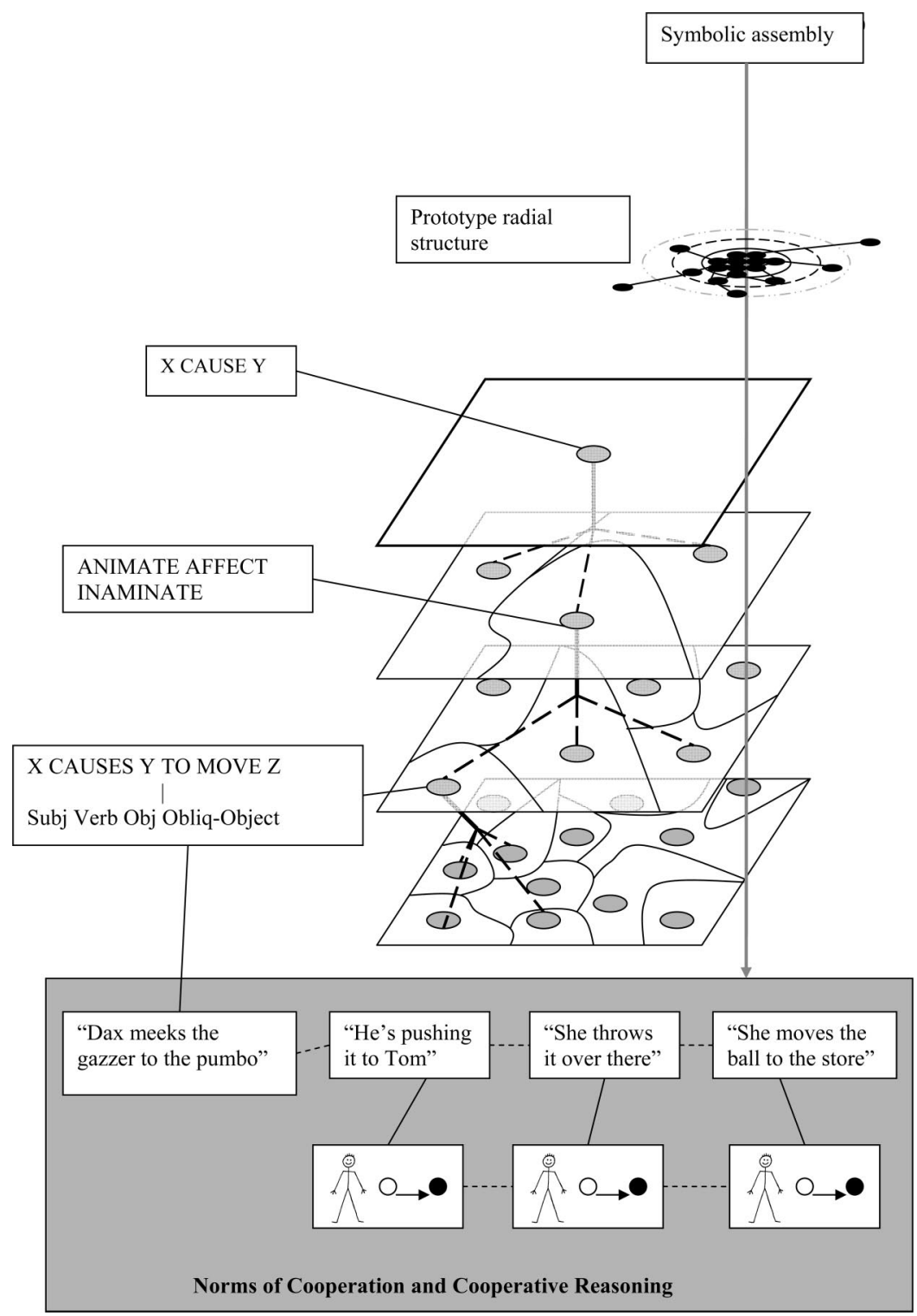

Figure 6. A four-plane abstraction of the $\mathrm{X}$ cause $\mathrm{Y}$ event, the caused-motion event forms part of this abstraction; the symbolic assembly is viewed through the four planes and incorporates the activated schemas it dominates. 
way the overall scene is construed is, in part, structured by the schematized meaning of the construction (Goldberg, 1995).

\section{Schema Productivity}

Therefore the key question is what happens when the child hears "the dax meeks the gazzer to the pumbo"? How do the various levels of abstraction in the form-function pairing of the causedmotion construction handle this novel utterance? (see Figure 6). Of course, the point of developing a step-by-step abstraction has been to try to show that at a schematic level of representation, by this stage in development, this utterance is not novel. Analogous meaning-form-event assemblies will have been encountered before (represented in the diagram by a links to other utterance forms and events). Is this justified?

Whether the infant has had opportunity to schematize the form will be a function of the frequency of the pattern in the input and how abstract the pattern is (a point expanded on later). Focusing on frequency, an extrapolation from one estimate of English child directed speech (but broadly corroborated by Wells, 1981) projects that infants hear something in the order of 7,000 utterances per day of which $15 \%$ have the "canonical" English Subject Verb Object (SVO) pattern (Cameron-Faulkner, Lieven, \& Tomasello, 2003). This works out as 383,250 exemplars of SVO utterances per year. This, of course, may not characterize the input heard by all children and the truth is no one really knows what the critical mass is to schematize a pattern given that infants are simultaneously learning everything else, ${ }^{4}$ but given this input frequency theories of learning have to consider the possibility that it might not be beyond the parallel processing power of 50 to 100 billion neurons with 100 trillion synaptic connections to detect such patterns in this distribution, especially when those patterns have sociocognitive pay-offs in being able to detect them-understanding and being understood.

In this example, frequency is calculated at a constructional level, but consider the type variability within the construction; without knowing the referents of dax, meek, and gazzer the recipient can still gain some information from the number of arguments in the discourse and the closed-class items that are highly likely to have been encountered before given their frequency. The morphological markers such as progressive-ing, prepositions, and determiners provide a skeleton structure from which a scene could in theory be reconstructed. Of course what would be missing would be the role that the participants were playing in such a scene, which is precisely what the caused-motion construction has grammaticalized. So in a sense, for the infant that hears this novel sentence the burden of processing is really on working out what dax, meeks, gazzer, and pumbo refer to. With reference to nothing else at all, the learner could only conclude that the referents are involved in some sort of caused-motion event. That said, it would be quite pragmatically odd to mention these things without respecting whether the recipient knows what these refer to, hence speakers spend time, at least at the start of discourse, establishing "what we know together" (not explicitly of course). Once communicators and recipients have anchored the referents, the constructional frame, in combination with the verb, structures the relationship between them - if all is well, then in such a way the communicator wants the scene to be construed in the mind of the recipient. ${ }^{5}$

\section{Item-Specific Knowledge and Generalizations}

Notice that as the schematicity has increased from level to level the semantic content has decreased (see Figure 6). This obviously represents a problem for a model of schematization if it cashes-out meaning as the output of the most abstract node: At the most general level it is schematic of everything and predictive of nothing. However, the symbolic assembly is a composite of all the levels it dominates, a form-function pairing. This is consistent with the evidence for graded representations of linguistic knowledge, in fact, one instantiation of this view-radial prototype conceptual structure-is produced as a by-product of "seeing" through the cumulative layers of abstraction, shown in Figure 6 as an arrow running from one end of the symbolic assembly to the other. Thus this is not a situation where we need to choose between supposedly dichotomous views of representations: we retain item-specific knowledge (e.g., exemplars) and we can abstract over them (e.g., prototypes). More important, after a period of development, the formal pole (toward the perceptual end) of this symbolic assembly may stop short of phonological content, that is, after sufficient evidence on which to generalize the construction can detach from the perceptual input. Thus, the caused motion schema comes to represent a grammaticalized event, free of phonological content in the sense that whether the noun phrase can enter the argument slots is not determined by its phonological properties.

This flexibility of analogy making is extremely impressive for many reasons, two of which are (i) it takes place at multiple levels of representation-from surface generalizations to functional generalizations and everything in between, and as a result of this (ii) the things being compared need not share any functional characteristics (a blue dog and a blue pencil are both blue) nor any perceptual characteristics (a blue taxi and a red boat are both means of transport). It is as if the flexibility of human thought allows us to mentally travel horizontally and vertically through different levels of abstraction, thus analogies made on the basis of how things behave can be made over vastly different degrees of specificity and domains (Genter, Ratterman, \& Forbus, 1993; Holyoak \& Koh, 1987). This includes the social-cognitive ability to understand you by analogy to myself (but never understand you as self, by definition), as well as the type of functional similarity that group constructions into families, such as ditransitives, resulatives, and caused motion or "the goat ate the woman" with "a woman tickled a goat." The adult state for such a network in

\footnotetext{
${ }^{4}$ Thus, the question is often asked "how is that children learn language so quickly?" (given that it is so fiendishly abstract and complicated) but one could as reasonably ask, "Why does it take them so long?" (given the experimental evidence that fast learning of novel construction is possible?; Casenhiser \& Goldberg, 2005). The problem with this line of reasoning is that it rarely spells out what pace of development is being compared to. It takes children as long as it does to accomplish $X$ and this is only surprising if it happens quicker/slower than a theory would predict for a certain input condition. The somewhat more interesting question is what factors predict an individual's developmental trajectory and developmental patterns in general.

${ }^{5}$ On this account cognitively incongruent utterances arise when there is a mismatch between the meaning potential (Allwood, 2003) or purport (Cruse, 2000) of the verb and the schematic meaning of the construction in which it appears, for example, He sleeps Mary, John received.
} 
usage-based theory is basically the memory traces of hundreds of thousands of usage events organized into families of form and function pairings. Because, at some point in development we detach from the perceptual input we can make concept-to-concept analogies, the type of abstraction out of which grammatical categories are formed. Figure 7 represents the process of analogy as a type of mental cut-and-paste operation, performed at different levels of abstraction (1 to 4 in Figure 7), in which hierarchies have a resonance with each other because of the relationships they encode (the objects, forces, goals, causes, paths, substances, etc. in the social-cognitive framework of Figure 2).

\section{The Distribution of the Input}

More important for putting together novel expressions, infants generalize over instances, but this is dependent on the character of what they are trying to learn, in short, the more abstract the pattern or correlation that one needs to detect, the more evidence one needs. To choose a nonlinguistic example, suppose an infant, over time, is exposed a variety of objects that are a variety of colors: most of the balls are red, most of the cars are yellow, most of the tables are white, and most of the birds are green. In the beginning (Table 1a), local contingencies emerge first as a result of the distributions of sampling, for example most of balls encountered in the life of that child up until this point are red. As the corpus of evidence grows (Table $1 \mathrm{~b}$ ) and as a function of the within- and between-category variance, the opportunity to abstract regularities arises, and this abstract regularity, in turn, makes shape and color a more important predictor of category membership. One could imagine further levels of abstraction in Table $1 \mathrm{a} / \mathrm{b}$, for example, if the more schematic category "wavelength" were in some sense predictive of the way shapes behave or vice versa. Before this second tier could be extracted above color we might need to add into the matrix, microwaves, $\mathrm{x}$-rays, and gamma rays. Color would then be an instance of wavelength (the visible spectrum) as would the other wavelengths (nonvisible spectrum) with each of these categories being schematic of those instances they dominate in the hierarchy-red, green, microwaves, and so forth The hypothesis is that the "depth" of the abstraction, represented in construction grammar as the taxonomic hierarchy, is proportional to the size of the matrix, which in the case of learning grammar means the size of the corpus of utterances. The usage-based prediction for learning is that the more abstract the schema (whether that be wavelength or caused motion) the more instances one needs to construct it.

The deep question is, for the infant what "counts" as an instance of a schema? The answer to this will obviously depend on the infant's stage of development, that is, the knowledge available for abstraction that is in the system at that time. For example, in the usage-based approach, the first time an infant hears an utterance of the form "john kicks mary," this cannot possibly be an instance of a transitive SVO schema as there needs to be at least two transitive utterances (instances of $x$ ) for a schema to be schematic of anything. In this sense, all utterances start life toward the more idiomatic end on the constructional continuum, the difference is that sentences of the form "john kicks mary" are destined to become subsumed (for an English learner) under a more general transitive SVO grammatical schema, whereas "the more the merrier" is destined to remain comparatively unproductive as it has comparatively fewer analogies with other families of constructions on the basis of form or function:

Table 1a. In the beginning local contingencies emerge first.

Table $1 \mathrm{~b}$. Only later do opportunities for abstraction occur as a function of the distributions and raw frequency (Sloutsky, 2003).

Thus the same item can treated of instances of different schemas at different points in development. This internal semantic reorganization is a major source of complexity for any theory trying to explain the development of language learning as the system begins internal redescriptions and self-organization on the basis of what a speaker knows (which itself is a shifting target). Emergent phenomena such as this require nonlinear interaction among compo-

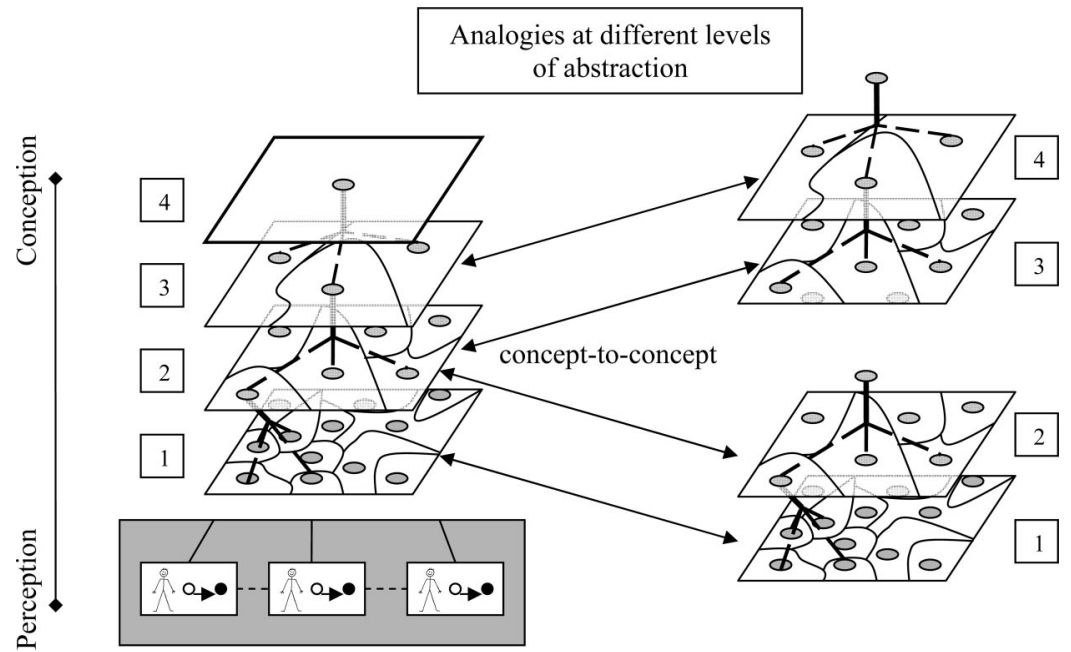

Figure 7. "Hierarchical resonance." Analogies are formed at various planes on the perceptual-conceptual continuum. 


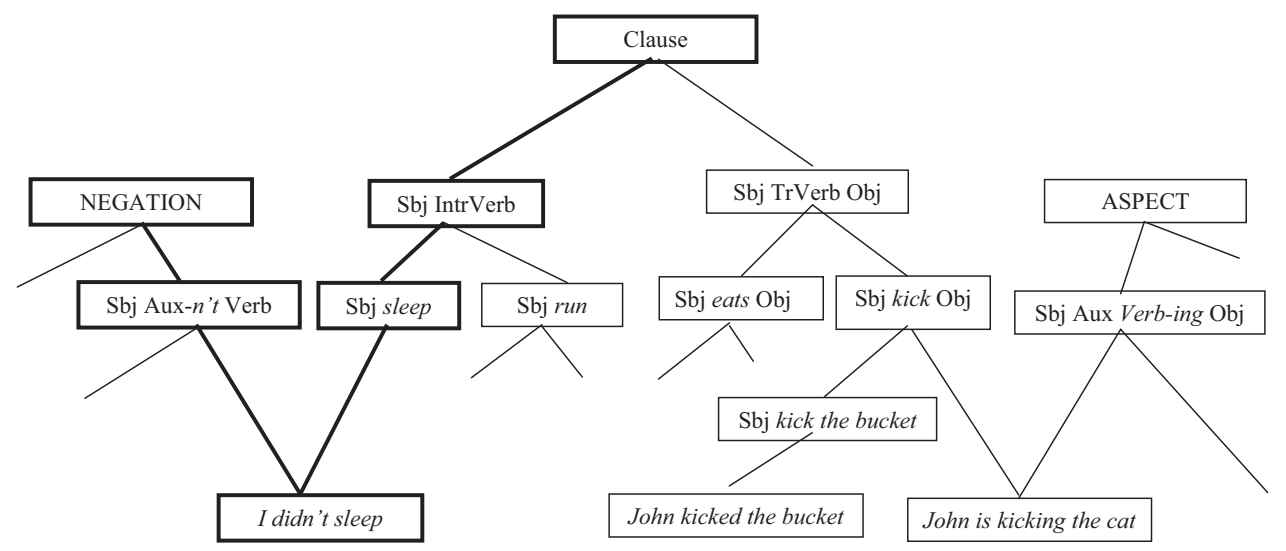

Figure 8. A network of related constructions.

nents of a system undergoing qualitative change, leading some cognitive scientists to seek insights from complexity science and dynamic systems theory to explain language development (Ninio, 2006; Thelen \& Smith, 1994; van Geert, 1991).

The other lesson from the matrix example is that the levels of abstraction are strongly determined by the training set and of course, what is functionally relevant to the individual's goals, for example, communicative motives. The example above considers the case in which the caused-motion construction emerges in development, but the stages of this abstraction (Figures 1, 4, 5) are obviously dependent on the structure and distribution of the input. I have tried to model these abstractions in stages that assume there are many other abstractions happening simultaneously (other blobs on the abstraction planes are not connected just because it would make it difficult to see what was going on in one section). One can imagine an instance in which caused-motion events are dominated directly by an $\mathrm{X}$ cause $\mathrm{Y}$ schema if there were no variation in the learning set, for example, we lived in a world where animacy was not predicative of any linguistic or event behavior. Indeed, as a by-product of sampling from the input one would expect some categories to start out this way (i.e., they are "underextended" or "overextended" with respect to an adult end-state), before being reorganized under the weight of new input evidence, a process which is similar to the conceptual reorganization of semantic knowledge in parallel distributed processing models (e.g., Rogers \& McClelland, 2008).

\section{The Endpoint: A Structured Inventory of Constructions}

In usage-based approaches such as cognitive grammar and construction grammar, linguistic constructions are symbolic assem-

Table 1a

In the Beginning Local Contingencies Emerge First

\begin{tabular}{lcccc}
\hline & Balls & Cars & Tables & Birds \\
\hline Red & 3 & 0 & 1 & 2 \\
Yellow & 2 & 3 & 0 & 1 \\
White & 1 & 2 & 3 & 0 \\
Green & 0 & 1 & 2 & 3 \\
$\downarrow$ & & & & \\
\hline
\end{tabular}

blies. Grammar is more than just a list of form-meaning pairs however; constructions are organized into a structured inventory, usually represented as a kind of taxonomic hierarchy. In Figure 8, inspired by the work of construction grammarian William Croft, the sentence "I didn't sleep" has multiple parent schemas (the inheritance network is highlighted in bold for this sentence). Thus, "I didn't sleep" is an instance of the more schematic (subject sleep), which in turn is an instance of the more schematic (subject intransitive verb), which in turn is an instance of the more schematic (clause). It also shares a parent schema (subject auxiliary - $n$ ' $t$ verb) meaning "I didn't sleep" is a instance of negation. In truth, this is a partial network, sentences are likely to belong to many more schematic families than I have been able to show here that interact in complex ways. "Kick the bucket" is represented by its own node because it is semantically idiosyncratic, yet it is dominated by the schematic (subject kick object) because it shares the same argument structure with more regular uses of transitive kick, such as "John is kicking the cat." "John is kicking the cat" is immediately dominated by the schema (subject kick object) and by progressive morphology -ing (subject auxiliary verb-ing object) meaning that the event of kicking is construed as ongoing. Note, the binary branches are purely diagrammatic, each construction is simply any one of a number of instances of the more schematic construction(s) in the hierarchy. Likewise, the sharply delineated boundaries of the categories are not to be taken literally; the evidence is that the relationships between elements are probabilistically instantiated in a network that allows room for gradable representations.

Table $1 \mathrm{~b}$

Only Later Do Opportunities for Abstraction Occur as a Function of the Distributions and Raw Frequency

\begin{tabular}{lcccr}
\hline & \multicolumn{4}{c}{ Shape } \\
\cline { 2 - 5 } Color & Balls & Cars & Tables & Birds \\
\hline Red & 10 & 1 & 3 & 5 \\
Yellow & 5 & 10 & 1 & 3 \\
White & 3 & 5 & 10 & 1 \\
Green & 1 & 3 & 5 & 10 \\
\hline
\end{tabular}




\section{Summary and Conclusions}

This account emphasized understanding the acquisition of function in the wider sociocultural context and physical grounding in which language is situated. I tried to describe a psychologically plausible escape from the circularity of concept learning: To learn a category one needs to know what the relevant features are; to know what the relevant features are assumes some knowledge of what the category is going to become. The main ideas presented here-for example, what something does forms the functional core of a concept-have all existed in the literature in various forms and (re)appeared at various times. The hope is that by bringing them together here I have been able to make what "abstracting over instances" means for a usage-based theorist a little clearer and more concrete. After all, if usage-based theories characterize acquisition as a developing inventory of form-function pairings, it is incumbent on those approaches to outline what they think develops and what form linguistic representations take. The development of representations proposed here is consistent with the mainstream view of grammar under a cognitive linguistics framework, whereby abstract entities are permissible, but only to the extent that these are schematic for actually occurring structures, and can be abstracted from actually occurring instances (Taylor, 2002).

An obvious objection to an experiential account of concept learning is that the caused-motion construction might be an example of "looking for the car keys under the street light," that is to say, out of all the constructions this is the most obviously grounded in an event. There is an analogy here with theories of embodied cognition that has faced similar objections, accused of focusing on concrete terms with tangible physical referents or instantiations. What about the concepts of justice, art, truth, crime, government, and so on? This is actually an argument in favor of the approach taken here. It could be argued that the meaning of abstract concepts such as life, liberty, and the pursuit of happiness can only be fully appreciated when considered in a wider body of knowledge about how people, institutions, and societies work. In this sense, learning syntax is learning that slice of culture that coerces people of the same speech community to communicate complex ideas "in this way."

Taking the developmental cognitive linguistics enterprise to its logical conclusion, one of the big questions is whether there are any purely linguistic representations or can all linguistic categories be traced back or decomposed into the functional or communicative roles they play. This is not, as some critics might say, "reducing" language to cognition any more than biology is being reduced to chemistry or chemistry is being reduced to physics. What it does mean is that it is a cognitive-science approach to language that is also concerned with the social foundations of human communication; a combination that is perversely rare in language research.

In summary, the co-occurrence of events and utterances offers a grounded way-in for infants to learn argument-structure constructions. Once the process of pairing form with function has begun, the redescription of representational levels takes over such that there is a complex interaction between events schematizing language and language schematizing events, ratcheting higher and higher levels of abstraction. By this process, over time, the causedmotion event is grammaticalized into the caused-motion construction, so that when a novel construction shares formal properties with previous usage events - that started life as utterance-event pairings - the construction by itself is enough to simulate the event in the mind of the recipient, and the targeted conception is communicated. Especially important in this explanation has been the fact that humans possess a unique set of social-cognitive and social motivational-skills that allow language to happen. Second, early language acquisition can only be explained with explicit reference to function - both in the sense that underlying concepts have a functional core and in the sense that linguistic categories are formed on the basis of communicative discourse functions (Nelson, 1996; Tomasello, 2003). This, combined with powerful pattern-detection skills, enables distributional regularities in the input to be paired with what the speakers intend to communicate.

\section{References}

Aissen, J. (1999). Markedness and subject choice in optimality theory. Natural Language and Linguistic Theory, 17, 673-711.

Allan, K. (1977). Classifiers. Language, 53, 285-311.

Allwood, J. (2003). Meaning potentials and context: Some consequences for the analysis of variation in meaning. In H. Cuyckens, R. Dirven, \& J. Taylor (Eds.), Cognitive approaches to lexical semantics (pp. 29-66). Berlin, Germany: Mouton de Gruyter.

Bakeman, R., \& Adamson, L. (1984). Coordinating attention to people and objects in mother-infant and peer-infant interactions. Child Development, 55, 1278-1289.

Baldwin, D. A. (1991). Infant contribution to the achievement of joint reference. Child Development, 62, 875-890.

Becker, M. (2007). Animacy, expletives, and the learning of the raisingcontrol distinction. In A. Belikova, L. Meroni, M. Umeda, (Eds.), Proceedings of the 2nd conference on generative approaches to language acquisition North America: Cascadilla proceedings project (pp. 12-20). Published by Cascadilla Proceedings Project, Somerville, MA, USA.

Berwick, R. (1985). The acquisition of syntactic knowledge. Cambridge, MA: MIT Press.

Braine, M. (1971). On two types of models of the internalization of grammars. In D. Slobin (Ed.), The ontogenesis of grammar: A theoretical symposium. New York, NY: Academic Press.

Braine, M., \& Brooks, P. (1995). Verb argument structure and the problem of avoiding an overgeneral grammar. In M. Tomasello \& W. Merriman (Eds.), Beyond names of things: Young children's acquisition of verbs (pp. 353-376). Hillsdale, NJ: Erlbaum.

Bruner, J. (1983). Child's talk. New York, NY: Norton.

Buresh, J., \& Woodward, A. L. (2007). Infants track action goals within and across agents. Cognition, 104, 287-314.

Bybee, J. L. (1985). Morphology: A study of the relation between meaning and form. Amsterdam, The Netherlands: Benjamins.

Cameron-Faulkner, T., Lieven, E., \& Tomasello, M. (2003). A construction based analysis of child directed speech. Cognitive Science, 27, 843-873.

Carpenter, M., Nagell, K., \& Tomasello, M. (1998). Social cognition, joint attention, and communicative competence from 9 to 15 months of age. Monographs of the Society for Research in Child Development, 63(4, Serial No. 255), i-vi, 1-174.

Carpenter, M., Akhtar, N., \& Tomasello, M. (1998). Fourteen- through 18-month-old infants differentially imitate intentional and accidental actions. Infant Behavior and Development, 21(2), 315-330.

Casenhiser, D., \& Goldberg, A. (2005). Fast mapping between a phrasal form and meaning. Developmental Science, 8, 500-508.

Choi, S., \& Bowerman, M. (1991). Learning to express motion events in English and Korean: The influence of language-specific lexicalization patterns. Cognition, 43, 83-121.

Chomsky, N. (1975). Reflections on Language. New York, Pantheon. 
Chomsky, N. (1980). Rules and Representations. Oxford, Blackwell.

Chomsky, N. (1995). The Minimalist Program. Cambridge, MA, MIT Press.

Comrie, B. (1981). Language universals and linguistic typology: Syntax and morphology. Chicago, IL: University of Chicago Press.

Croft, W. (2001). Radical Construction Grammar: syntactic theory in typological perspective. Oxford University Press.

Cruse, A. D. (2000). Meaning in language. Oxford, England: Oxford University Press.

Denny, J. P. (1976). What are noun classifiers good for? In S. S. Mufwenen, et al. (Eds.), Papers from the 12th regional meeting, Chicago Linguistic Society (pp. 122-132). Chicago: Chicago Linguistic Society.

Dowty, D. (1991). Thematic proto-roles and argument selection. Language, 67, 547-619.

Gelman, S. A., \& Koenig, M. A. (2001). The role of animacy in children's understanding of move. Journal of Child Language, 28, 683-701.

Gentner, D. (1982). Why nouns are learned before verbs: Linguistic relativity versus natural partitioning. In S. A. Kuczaj (Ed.), Language development: Vol. 2. Language, thought and culture (pp. 301-334). Hillsdale, NJ: Erlbaum.

Gentner, D., \& Bowerman, M. (2009). Why some spatial semantic categories are harder to learn than others: The typological prevalence hypothesis. In J. Guo, E. Lieven, S. Ervin-Tripp, N. Budwig, S. Özçaliskan, \& K. Nakamura (Eds.), Crosslinguistic approaches to the psychology of language: Research in the tradition of Dan Isaac Slobin (pp. 465-480). New York, NY: Erlbaum.

Gentner, D., \& Markman, A. B. (1993). Analogy-watershed or Waterloo? Structural alignment and the development of connectionist models of cognition. In S. J. Hanson, J. D. Cowan, \& C. L. Giles (Eds.), Advances in neural information processing systems 5 (pp. 855-862). San Mateo, CA: Kaufmann.

Gentner, D., \& Markman, A. B. (1994). Structural alignment in comparison: No difference without similarity. Psychological Science, 5, 152158

Gentner, D., \& Markman, A. B. (1995). Similarity is like analogy: Structural alignment in comparison. In C. Cacciari (Ed.), Similarity in language, thought and perception (pp. 111-147). Brussels, Belgium: BREPOLS.

Gentner, D., \& Markman, A. B. (1997). Structure mapping in analogy and similarity. American Psychologist, 52, 45-56.

Gentner, D., \& Medina, J. (1998). Similarity and the development of rules. Cognition, 65, 263-297.

Gentner, D., Ratterman, M. J., \& Forbus, K. (1993). The roles of similarity in transfer: Separating retrievability from inferential soundness. Cognitive Psychology, 25, 524-575.

Gergely, G., Bekkering, H., \& Király, I. (2002). Rational imitation in preverbal infants. Nature, 415,755

Gleitman, L. R., January, D., Nappa, R., \& Trueswell, J. C. (2007). On the give and take between event apprehension and utterance formulation. Journal of Memory and Language, 57(4), 544-569.

Griffin, Z. M., \& Bock, K. (2000). What the eyes say about speaking. Psychological Science, 11, 274-279.

Göksun, T., Hirsh-Pasek, K., \& Golinkoff, R. M. (2008, July). Figure and ground: Conceptual primitives for processing events. In T. Göksun \& S. Pruden (Chairs), Foundations for learning relational terms: What is in an event? Symposium conducted at the Eleventh International Congress for the Study of Child Language, Edinburgh, Scotland.

Göksun, T., Hirsh-Pasek, K., \& Golinkoff, R. M. (2010). Trading spaces: Carving up events for learning language. Perspectives on Psychological Science, 5, 33-42.

Goldberg, A. (1995). Constructions: A construction grammar approach to argument structure. Chicago, IL: University of Chicago Press.

Goldberg, A. (2006). Constructions at work: The nature of generalisations in language. Oxford, England: Oxford University Press.
Goldstone, R. L. (1994). The role of similarity in categorization: Providing a groundwork. Cognition, 52, 125-157.

Goldstone, R. L., \& Medin, D. L. (1994). Interactive activation, similarity, and mapping: An overview. In K. Holyoak \& J. Barnden (Eds.), Advances in connectionist and neural computation theory, Vol. 2: Analogical connections (pp. 321-362). Hillsdale, NJ: Ablex.

Goldstone, R. L., Medin, D. L., \& Gentner, D. (1991). Relational similarity and the non-independence of features in similarity judgments. Cognitive Psychology, 23, 222-264.

Golinkoff, R. M. (1975). Semantic development in infants: The concepts of agent and recipient. Merrill-Palmer Quarterly, 21, 181-193.

Hespos, S. J., \& Spelke, E. S. (2004). Conceptual precursors to language. Nature, 430, 453-456.

Holyoak, K. J., \& Koh, K. (1987). Surface and structural similarity in analogical transfer. Memory \& Cognition, 15, 332-340.

Inagaki, K., \& Hatano, G. (1987). Young children's spontaneous personification as analogy. Child Development, 58, 1013-1020.

Jackendoff, R. (1983). Semantics and cognition. Cambridge, MA: MIT Press.

Karmiloff-Smith, A. (1979). A functional approach to child language Cambridge, England: Cambridge University Press.

Karmiloff-Smith, A. (1992). Beyond modularity: A developmental perspective on cognitive science. Cambridge, MA: MIT Press/Bradford Books.

Kemmer, S. (2003). Human cognition and the elaboration of events: Some universal conceptual categories. In M. Tomasello (Ed.), The new psychology of language: Cognitive and functional approaches to language structure (Vol. 2, pp. 89-118). Mahwah, NJ: Erlbaum.

Kibrik, A. E. (1985). Toward a typology of ergativity. In J. Nichols \& A. Woodbury (Eds.), Grammar inside and outside the clause (pp. 268 324). Cambridge, England: Cambridge University Press.

Kodama, K. (2004). "The English Caused-Motion Construction Revisited-A Cognitive Perspective," Papers in Linguistic Science, No. 10, pp. $41-54$

Lakoff, G. (1987). Cognitive models and prototype theory. In U. Neisser (Ed.), Concepts and conceptual development: Ecological and intellectual factors in categorization. Emory symposia in cognition (Vol. 1, pp. 63-100). Cambridge, England: Cambridge University Press.

Lakoff, G., \& Johnson, M. (1999). Philosophy in the flesh: The embodied mind and its challenge to western thought. New York, NY: Basic Books.

Lakusta, L., Wagner, L., O'Hearn, K., \& Landau, B. (2007). Conceptual foundations of spatial language: Evidence for a goal bias in infants. Language Learning and Development, 3, 179-197.

Langacker, R. (1987). Foundations of cognitive grammar (Vol. 1). Stanford, CA: Stanford University Press.

Mallinson, G., \& Blake, B. (1981). Language typology: Cross-cultural studies in syntax. Amsterdam, The Netherlands: North-Holland.

Mandler, J. M. (1992). How to build a baby: II. Conceptual primitives. Psychological Review, 99, 587-604.

Mandler, J. M. (2004). The foundations of mind: Origins of conceptual thought. Oxford, England: Oxford University Press.

Massey, C., \& Gelman, R. (1988). Preschooler's ability to decide whether a photographed unfamiliar object can move itself. Developmental Psychology, 24, 307-317.

McDonough, L., Choi, S., \& Mandler, J. M. (2003). Understanding spatial relations: Flexible infants, lexical adults. Cognitive Psychology, 46, 229-259.

Nappa, R., Wessel, A., McEldoon, K. L., Gleitman, L., \& Trueswell, J. C. (2009). Use of Speaker's Gaze and Syntax in Verb Learning. Language Learning and Development, 5, 203-234.

Nelson, K. (1983). The derivation of concepts and categories from event representations. In E. K. Scholnick (ed.), New trends in conceptual representation: Challenges to Piaget's theory? (pp. 129-149). Hillsdale, NJ: Erlbaum. 
Nelson, K. (1985). Making sense: The acquisition of shared meaning. New York, NY: Academic Press.

Nelson, K., (1996). Language in cognitive development. New York, NY: Cambridge University Press.

Ninio, A. (2006). Language and the learning curve: A new theory of syntactic development. Oxford, England: Oxford University Press.

Papafragou, A., Cassidy, K., \& Gleitman, L. (2007). When we think about thinking: The acquisition of belief verbs. Cognition, 105, 125-165.

Perfors, A., Tenenbaum, J. B., \& Wonnacott, E. (2010). Variability, negative evidence, and the acquisition of verb argument constructions. Journal of Child Language, 37, 607-642.

Pinker, S. (1989). Learnability and cognition: The acquisition of verbargument structure. Cambridge, MA: MIT Press/Bradford Books.

Poulin-Dubois, P., \& Forbes, J. (2002). Toddlers' attention to intentionsin-action in learning novel action words. Developmental Psychology, 38, $104-114$.

Pulverman, R., Golinkoff, R. M., Hirsh-Pasek, K., \& Sootsman-Buresh, J. (2008). Infants discriminate paths and manners in non-linguistic dynamic events. Cognition, 108, 825-830.

Rogers, T. T., \& McClelland, J. L. (2008). Precis of semantic cognition, a parallel distributed processing approach. Behavioral and Brain Sciences, 31, 689-749.

Saussure, Ferdinand de. ([1916] 1983). Course in General Linguistics (trans. Roy Harris). London: Duckworth.

Sloutsky, V. M. (2003). The role of similarity in the development of categorization. Trends in Cognitive Sciences, 7, 246-251.

Smith, C. B., Adamson, L. B., \& Bakeman, R. (1988). Interactional predictors of early language. First Language, 8, 143-156.

Song, J. (2001). Linguistic typology: Morphology and syntax. London, England: Longman.

Sperber, D., \& Wilson, D. (1986). Relevance: Communication and cognition. Cambridge, MA: Harvard University Press.

Sperber, D., \& Wilson, D. (1995). Relevance: Communication and cognition (2nd ed.). Oxford, England: Blackwell.

Talmy, L. (1985). Lexicalization patterns: Semantic structure in lexical forms. In T. Shopen (Ed.), Grammatical categories and the lexicon. Language typology and syntactic description (Vol. 3, pp. 57-149). New York, NY: Cambridge University Press.
Talmy, L. (1988). Force dynamics in language and cognition. Cognitive Science, 12, 49-100.

Talmy, L. (2000). Toward a cognitive semantics. Cambridge, MA: MIT Press.

Taylor, J. (2002). Cognitive grammar. Oxford, England: Oxford University Press.

Thelen, E., \& Smith, L. B. (1994). A dynamic systems approach to the development of cognition and action. Cambridge, MA: MIT Press.

Tomasello, M. (1992). The social bases of language acquisition. Social Development, 1, 67-87.

Tomasello, M. (2003). Constructing a language: A usage-based theory of language acquisition. Cambridge, MA: Harvard University Press.

Tomasello, M. (2008). Origins of human communication. Cambridge, MA: MIT Press.

Tomasello, M., \& Barton, M. (1994). Learning words in nonostensive contexts. Developmental Psychology, 30, 639-650.

Tomasello, M., Mannle, S., \& Kruger, A. C. (1986). Linguistic environment of 1- to 2-year old twins. Developmental Psychology, 22, 169-176.

Tomasello, M., \& Todd, J. (1983). Joint attention and lexical acquisition style. First Language, 4, 197-212.

Trevarthen, C., \& Hubley, P. (1978). Secondary intersubjectivity: confidence, confiding and acts of meaning in the first year. In A. Lock (ed.), Action, Gesture and Symbol: The emergence of language (pp. 183-230). London: Academic Press.

van Geert, P. (1991). A dynamic system model of cognitive and language growth, Psychological Review, 98, 3-53.

Wells, G. (1981). Learning through interaction: The study of language development. Cambridge, England: Cambridge University Press.

Wolff, P. (2007). Representing causation. Journal of Experimental Psychology: General, 136, 82-111.

Woodward, A. L., \& Sommerville, J. A. (2000). Twelve-month-old infants interpret action in context. Psychological Science, 11, 73-77.

Received June 21, 2011

Revision received August 17, 2011

Accepted August 25, 2011

\section{E-Mail Notification of Your Latest Issue Online!}

Would you like to know when the next issue of your favorite APA journal will be available online? This service is now available to you. Sign up at http://notify.apa.org/ and you will be notified by e-mail when issues of interest to you become available! 